University for Business and Technology in Kosovo

UBT Knowledge Center

UBT International Conference

2013 UBT International Conference

Nov 2nd, 12:00 PM - 12:15 PM

\title{
Effective Interest Rate of Different Loans
}

Ramadan Limani

University for Business and Technology, r_limani@yahoo.com

Follow this and additional works at: https://knowledgecenter.ubt-uni.net/conference

Part of the Business Commons

\section{Recommended Citation}

Limani, Ramadan, "Effective Interest Rate of Different Loans" (2013). UBT International Conference. 39.

https://knowledgecenter.ubt-uni.net/conference/2013/all-events/39

This Event is brought to you for free and open access by the Publication and Journals at UBT Knowledge Center. It has been accepted for inclusion in UBT International Conference by an authorized administrator of UBT Knowledge Center. For more information, please contact knowledge.center@ubt-uni.net. 


\title{
Effective Interest Rate of Different Loans
}

\author{
Ramadan Limani \\ Faculty of MBE, UBT \\ E-mail: ramadan.limani@ubt-uni.netr_limani@yahoo.com
}

\begin{abstract}
Abs tract. In this paper several types of loans offered by banks and other micro financial institutions are shown, and their respective effective interest rates are calculated. The parameters that affect the effective interest rate, which is the only real parameter that shows whether a loan is affordable or not, are considered. Some examples of loans without a fee, and those with fees are given and the effective interest rate for those loans is calculated. The mathematical technique for calculation of the effective interest rate is shown, and the financial consultant CASIO FC $-100 \mathrm{~V}$ is used to mathematically calculate the effective interest rate.
\end{abstract}

Keywor ds: nominal interest rate, periodical interest rate, effective interest rate, fee.

\section{Introduction}

In financial mathematics and in banking, deposits and loans play an important role. In case of deposits and loans without a fee the only parameter that affects the effective interest rate is $\mathrm{C} / \mathrm{Y}$, which is equal to the number of compounding per year, and it expresses the frequency of interest capitalization in a year. In case of loans with a fee, apart the parameter $\mathrm{C} / \mathrm{Y}$, there are two other parameters that have huge impact on the value of the effective interest rate: the value of the fee and the maturity period of the loan. We will notice that the shorter the period of maturity is the higher the effective interest is, and of course the higher the fee is the higher the effective interest is. It is obvious that the effective interest rate of a loan shows the "quality" of the loan. In other words the effective interest rate tells the customer whether the loan is affordable or not. In many countries in the world, bank loan officers hide the effective interest rate when a customer asks for a loan. They often show only the nominal interest rate and the fee but not the effective interest rate. They do not tell the customer the value of the effective interest rate, because its value is often pretty higher than the value of the nominal interest rate, and thus they may lose the customer. Ordinary people find it difficult to calculate even the effective interest rate of loans without a fee, while calculating the effective interest rate for loans with a fee (or fees) is a hard mathematical problem, and it can be calculated by using approximation mathematical methods for solving algebraic equations of higher degrees. Nowadays, thanks to technology we can do this in a few seconds, but we must keep in mind that a financial calculator performs millions of iterations and instructions in ord er to solve the problem.

\subsection{Loans without a fee}

In this section we consider a loan without a fee and we calculate the effective interest rate. We suppose that the value of principal is $P$, the number of equal periodical installments is $n$, the number of compounding per year is $C Y=c$, and finally the frequency of installments per year is $P Y=p$. As we know, the value of equal periodical installments, denoted by $a$, is calculated by formula:

$$
a=P \cdot \text { ip } 1-q p-n,
$$

where $q p=1+i c \quad c p, i p=q p-1$, and the value of $i p$ is called periodical interest rate. In this case, the value of the effective interest rate depends only on the number $c$, and its value is

$$
\text { i eff }=1+i c \quad c-1 \text {. }
$$

Example 1.1.1. Suppose we have a loan of 5000 EUR with the nominal interest rate $i=8 \%$, and the maturity is 10 months. The interest is compounded quarterly and the installments are monthly. We are interested in calculating the installments and the effective interest rate. 
End; $i=8 \% ; C / Y=4 ; P / Y=12 ;$ m-months

Fig. 1.1 First, we find the capitalization factor $q p=1+i c \quad c p=1+0.084412=1+$ $0.08413=1.00662271$, while the value of monthly installments is $a=P \cdot i p 1-q p-n=$ $5000 \cdot i p 1-q p-10=518.39$ EUR. The effective interest rate is :

$i$ eff $=q p p=1+i c \quad c-1=1+0.0844-1=8.24 \%$.

Using the financial consultant FC-100V we have:

END; $N=10 ; I \%=8 ; P V=-5000 ; F V=0 ; P / Y=12 ; C / Y=4 ; E S C: S O L V E: P M T=518.39$

The instructions of this line help us calculate the value of monthly installments $(\mathrm{P} / \mathrm{Y}=12)$.

ESC: CNVR: N=4; I\%=8; SOLVE: EFF=8.24

The instructions of this line help us calculate the value of the effective interest rate (EFF). The number $\mathrm{N}$ stands for the number of compounding per year $(\mathrm{N}=\mathrm{C} / \mathrm{Y}=4)$.

Example 1.1.2. We consider the same loan of 5000 EUR with the same nominal interest rate as in Example 1.1.1, and with 10 equal quarterly installments $(\mathrm{P} / \mathrm{Y}=4)$ and monthly compounding $(\mathrm{C} / \mathrm{Y}=12)$. The value of the installments and the effective interest rate are:

$$
\begin{aligned}
& a=P \cdot i p 1-q p-n=5000 \cdot i p 1-q p-10=557.02 \mathrm{EUR}, \\
& q p=1+i c \quad c p=1+0.0812124=1+0.08123=1.02013363 \\
& i \text { eff }=1+i c \quad c-1=1+0.081212-1=8.3 \%,
\end{aligned}
$$

respectively.

Using financial consultant FC-100V we have:

\section{$\mathrm{END} ; \mathrm{N}=10 ; \mathrm{I} \%=8 ; \mathrm{PV}=\mathbf{5 0 0 0} ; \mathrm{FV}=0 ; \mathrm{P} / \mathrm{Y}=4 ; \mathrm{C} / \mathrm{Y}=12 ; \mathrm{ESC}: \mathrm{SOLVE}: \mathrm{PMT}=557.02$}

The instructions of this line help us calculate the value of quarterly installments $(\mathrm{P} / \mathrm{Y}=4)$.

\section{ESC: CNVR: $N=12 ; 1 \%=8 ;$ SOLVE: $\mathrm{EFF}=8.3$}

The instructions of this line help us calculate the value of the effective interest rate (EFF). The number $\mathrm{N}$ stands for the number of compounding periods per year $(\mathrm{N}=\mathrm{C} / \mathrm{Y}=12)$.

It is obvious that the effective interest rate in Example 1.1.2 is higher than that of Example 1.1.1. This happens because the frequency of compounding per year in Example 1.1.2 is higher than that in Example 1.1.1.

In case of continuous compounding, i.e. $c=C / y \rightarrow \infty$, and $p=P / Y$, we have :

$q p=\lim c \rightarrow \infty 1+i c \quad c p=e i p$, whereas $i p=q p-1$.

In this case the effective interest rate is:

i eff $=\lim c \rightarrow \infty 1+i c c-1=$ e $i-1$.

Example 1.1.3. Let us consider the same loan of Example 1.1.1 but with continuous compounding. In this case the value of monthly installments is

$a=P \cdot i p 1-q p-n=5000 \cdot i p 1-q p-10=518.58 \mathrm{EUR}$, where

$q p=\lim c \rightarrow \infty 1+i c \quad c p=e i p=e 0.0812=1.006688938$, and $i p=q p-$ $1=0.006688938$. 
The value of the effective interest rate is:

$i$ eff $=e i-1=e 0.08-1=8.33 \%$.

End, $i=8 \% ; C / Y=\infty ; P / Y=12 ; m-m o n t h s$

Fig. 1.2

There is no mode in FC-100V, since the maximum value of the parameter $\mathrm{C} / \mathrm{Y}$ is limited to 9999.

\subsection{Loans with a disbursement fee}

In this section we consider a loan with a disbursement fee $f$, and we calculate the effective interest rate. Let us suppose that the value of principal is $P$, the number of periodical installments is $n$, the number of compounding per year is $C Y=c$, and finally the frequency of installments per year is $P Y=p$. As we know, the value of equal installments, denoted by $a$, is calculated by formula:

$a=P \cdot i p 1-q p-n$,

where $q p=1+i c \quad c p$, and $i p=q p-1$. In this case, the value of the effective interest rate does not depend only on the number $c$, but it also depends on the value of disbursement fee $f$ and the period of loan maturity. In order to notice the difference we consider some examples from section 1.1, but applying a disbursement fee $\mathrm{f}=2 \%$ of the principal $\mathrm{P}$.

Example 1.2.1. Suppose we have a loan of 5000 EUR with the nominal interest rate $i=8 \%, 10$ month maturity and with a disbursement fee $\mathrm{f}=2 \%$ of the principal $\mathrm{P}=100 \mathrm{EUR}$. The interest is compounded quarterly and the installments are monthly. We are interested in calculating the installments and the effective interest rate.

The value of 10 monthly installments is the same as in Example $1.1 .1 a=5000 \cdot i p 1-q p-$ $10=518.39 \mathrm{EUR}, q p=1.00662271$. The difference between two cases is that in Example 1.2.1 the customer gets 4900 EUR from the bank, not 5000 EUR as he or she will get from the bank in Example 1.1.1. So we expect that the value of the effective interest rate in Example 1.2.1 will be higher than that of Example 1.1.1.

Let us consider general case. As we know, the relation between relevant parameters of a loan is given by the equation:

$P \cdot q p n=a \cdot q p n-1+a \cdot q p n-2+\cdots+\cdot q p+a=a \cdot q p n-1 q p-1=a \cdot$

$q p n-1$ i $p$

or

$P \cdot q p n+1-P+a \cdot q p n+a=0$.

However, the customer gets $P-f$, say EUR, and the loan has to be repaid with $n$ installments, and in this case the capitalization factor $q p^{\prime}$ is greater than the previous one $q p$. Thus, the parameter $q p^{\prime}$ is a solution to the equation:

$(P-f) \cdot q p^{\prime} n+1-P-f+a \cdot q p^{\prime} n+a=0$.

(1)

The degree of the previous algebraic equation is $n+1$, and as we know we can mathematically solve it for $n=1,2,3$, while for $n \geq 4$, we can only find approximate solutions. It is proved that the equation (1) has only one real solution on $q p^{\prime}>1$. After finding this solution we can easily calculate the value of the effective interest rate by formula:

i eff $=q p^{\prime} p-1$. 
Let us use the financial consultant FC-100V to calculate the effective interest rate in Example 1.2.1.

$\mathrm{END} ; \mathrm{N}=10 ; \mathrm{I} \%=8 ; \mathrm{PV}=-5000 ; \mathrm{FV}=0 ; \mathrm{P} / \mathrm{Y}=12 ; \mathrm{C} / \mathrm{Y}=4 ; \mathrm{ESC}: \mathrm{SOLVE}: \mathrm{PMT}=518.39$

The instructions of this line help us calculate the value of monthly installments $(\mathrm{P} / \mathrm{Y}=12)$.

ESC: PV=-5000+100; SOLVE: $1 \%=12.58$

This line of instructions helps us find the nominal interest rate for the loan of $-5000+100=-4900$ EUR. The other parameters have not been changed, and so rewriting them is omitted. Of course the new value of the nominal interest rate is higher than $8 \%$. This happens since the customer gets $4900 \mathrm{EUR}$, not 5000 EUR. Finally, we use the conversion mode to find the value of the effective interest rate:

ESC: CNVR: N=4; SOLVE: EFF=13.19

Again, rewriting of the final value of $\mathrm{I} \%$ is omitted, since the calculator keeps in memory last parameter values.

As we notice the value of the effective interest rate is $13.19 \%$.

Next example shows that the shorter the period of loan maturity is the higher the effective interest rate will be and the converse.

Example 1.2.2. Suppose we have a loan of $\mathrm{P}=5000$ EUR with the nominal interest rate $i=8 \%, 4$ month maturity and with a disbursement fee $\mathrm{f}=2 \%$ of principal $\mathrm{P}=100$ EUR. The interest is compounded quarterly and the installments are monthly. We are interested in calculating the installments and the effective interest rate.

The value of 4 monthly installments is equal to $a=5000 \cdot i p 1-q p-4=1270.76$ EUR, $q p=1.00662271$. To calculate the effective interest rate we use the financial consultant FC-100V.

END; $\mathrm{N}=4 ; \mathrm{I} \%=8 ; \mathrm{PV}=-5000 ; \mathrm{FV}=0 ; \mathrm{P} / \mathrm{Y}=12 ; \mathrm{C} / \mathrm{Y}=4 ; \mathrm{ESC}: \mathrm{SOLVE}: \mathrm{PMT}=1270.76$

This line helps us calculate the value of monthly installments.

ESC: $P V=-5000+100 ;$ SOLVE: $I \%=18.07$

This line helps us calculate the value of the nominal interest rate after applying the fee.

Since the compounding is quarterly $(\mathrm{C} / \mathrm{Y}=4)$, we have to calculate the effective interest rate.

\section{ESC: CNVR: N=4; SOLVE: $\mathrm{EFF}=19.33$}

Finally, the effective interest rate of Example 1.2 .2 is $19.33 \%$.

Example 1.2.3. If the same loan from Example 1.2.3 with the same conditions but it has to be repaid by 2 monthly equal installments, then the effective interest rate will be higher than that from Example 1.2.2.

To notice this, we use the same technique and the same calculator FC-100V.

The value of 2 monthly installments is equal to $a=5000 \cdot i p 1-q p-2=2524.86$ EUR, $q p=1.00662271$. After using the financial consultant FC-100V we have:

$\mathrm{END} ; \mathrm{N}=2 ; \mathrm{I} \%=8 ; \mathrm{PV}=-5000 ; \mathrm{FV}=0 ; \mathrm{P} / \mathrm{Y}=12 ; \mathrm{C} / \mathrm{Y}=4 ; \mathrm{ESC}: \mathrm{SOLVE}: \mathrm{PMT}=2524.86$

This line helps us calculate the value of monthly installments.

ESC: $P V=-5000+100 ;$ SOLVE: $I \%=24.86$

This line helps us calculate the value of the nominal interest rate after applying the fee. 
Since the compounding is quarterly $(\mathrm{C} / \mathrm{Y}=4)$, we have to calculate the effective interest rate.

ESC: CNVR: $N=4$; SOLVE: $E F F=27.28$

Finally, the effective interest rate of Example 1.2 .3 is $27.28 \%$, which is obvious pretty higher than that from Example 1.2.2.

If we summarize all above examples, we get the following table.

\begin{tabular}{|c|c|c|c|c|c|c|}
\hline \multirow{3}{*}{$\begin{array}{l}\text { Principal } \\
\text { Nom. int. rate }\end{array}$} & \multicolumn{6}{|c|}{$P=5000$ EUR } \\
\hline & \multicolumn{6}{|l|}{$i=8 \%$} \\
\hline & $\mathrm{C} / \mathrm{Y}$ & $\mathrm{P} / \mathrm{Y}$ & Fee in EUR & $\begin{array}{l}\text { Number } \\
\text { inst. }\end{array}$ & of & Eff. int. rate \\
\hline 1. & 4 & 12 & 0 & 10 & & $8.24 \%$ \\
\hline 2. & 12 & 4 & 0 & 10 & & $8.30 \%$ \\
\hline 3. & $\infty$ & 12 & 0 & 10 & & $8.33 \%$ \\
\hline 4. & 4 & 12 & 100 & 10 & & $13.19 \%$ \\
\hline 5. & 4 & 12 & 100 & 4 & & $19.33 \%$ \\
\hline 6. & 4 & 12 & 100 & 2 & & $27.28 \%$ \\
\hline
\end{tabular}

\section{References}

1 Buchanan, J.R. (2010) The Theory of Interest (An Undergraduate Introduction to Financial Mathematics), Millers ville University, USA.

2 Finan, M.B. (2012): A semester Course in Finite Mathematics for Business and Economics, Arkansas Tech University, Department of Mathematics, USA.

3 Ohse, D. (2010) Financial Mathematics, ProCredit Academy GmbH, Fürth-Weschnitz, Germany. 